\title{
Observed and modeled surface eddy heat fluxes in the eastern Nordic Seas
}

\author{
P. E. Isachsen, ${ }^{1}$ I. Koszalka, ${ }^{2}$ and J. H. LaCasce ${ }^{3}$ \\ Received 30 January 2012; revised 27 June 2012; accepted 29 June 2012; published 18 August 2012.
}

[1] Large-scale budget calculations and numerical model process studies suggest that lateral eddy heat fluxes have an important cooling effect on the Norwegian Atlantic Current (NwAC) as it flows through the Nordic Seas. But observational estimates of such fluxes have been lacking. Here, wintertime surface eddy heat fluxes in the eastern Nordic Seas are estimated from surface drifter data, satellite data and an eddy-permitting numerical model. Maps of the eddy heat flux divergence suggest advective cooling along the path of the NwAC. Integrating the flux divergence over temperature classes yields consistent estimates for the three data sets; the waters warmer than about $6^{\circ} \mathrm{C}$ are cooled while the cooler waters are warmed. Similar integrations over bottom depth classes show that regions shallower than about $2000 \mathrm{~m}$ are cooled while deeper regions are warmed. Finally, integrating the flux divergence along the core of the NwAC suggests that the highest eddy-induced heat loss at the surface is along the steepest part of the continental slope, east of the Lofoten Basin. The model fields indicate that cooling of the current by lateral eddy fluxes is comparable to or larger than the local heat loss to the atmosphere.

Citation: Isachsen, P. E., I. Koszalka, and J. H. LaCasce (2012), Observed and modeled surface eddy heat fluxes in the eastern Nordic Seas, J. Geophys. Res., 117, C08020, doi:10.1029/2012JC007935.

\section{Introduction}

[2] The Nordic Seas, lying between the North Atlantic and Arctic oceans, play a central role in the global thermohaline circulation. It is here that the northernmost limb of the warm Atlantic Water experiences the final cooling that makes it dense enough to feed the lower North Atlantic Deep Water. As seen for example in air-sea fluxes, this cooling occurs largely in the eastern Nordic Seas [Mauritzen, 1996a, 1996b; Isachsen et al., 2007; Eldevik et al., 2009; Segtnan et al., 2011], in the vicinity of the Norwegian Atlantic Current (NwAC), along the continental slope off Norway (Figure 1). But cooling also occurs over the deep Lofoten and Norwegian basins, west of the NwAC. So it is likely there is an active exchange occurring between the NwAC and those basins. But the large-scale currents are probably not responsible since they are strongly steered by topography in this region [Poulain et al., 1996; Orvik and Niiler, 2002; Jakobsen et al., 2003; Nøst and Isachsen, 2003; Isachsen et al., 2003; Voet et al., 2010].

\footnotetext{
${ }^{1}$ Research Department, Norwegian Meteorological Institute, Oslo, Norway.

${ }^{2}$ Department of Earth and Planetary Sciences, Johns Hopkins University, Baltimore, Maryland, USA.

${ }^{3}$ Institute of Geoscience, University of Oslo, Oslo, Norway.

Corresponding author: P. E. Isachsen, Research Department, Norwegian Meteorological Institute, Postboks 43, Blindern, NO-0313 Oslo, Norway. (p.e.isachsen@met.no)

C2012. American Geophysical Union. All Rights Reserved. 0148-0227/12/2012JC007935
}

[3] In numerical models [Spall, 2004, 2005, 2010a, 2010b; Walin et al., 2004; Köhl, 2007] the exchange is mediated by mesoscale eddies. Such eddy transport has also been inferred from observations [Rossby et al., 2000; Andersson et al., 2011; Koszalka et al., 2011a; Isachsen and Nøst, 2012]. The eddies, which are ubiquitous here, originate in the NwAC and are of deformation scale or larger. Indeed, the situation in the eastern Nordic Seas is very similar to that in the Labrador Sea, where eddies from the boundary current southwest of Greenland transport freshwater and heat into the deep basins [Lilly et al., 2003; Katsman et al., 2004; Straneo, 2006].

[4] The necessity of lateral exchange can also be seen from Lagrangian considerations. A fluid parcel moving in the core of the NwAC would make the transit from the Greenland-Scotland Ridge in the south to the Svalbard islands in the north in a matter of months. With such brief contact with the atmosphere, one could not account for the observed decrease in temperature in the current [Mauritzen, 1996a, 1996b]. So fluid parcels must be exiting the current and spending longer periods in the interior regions of the Nordic Seas. This picture was confirmed recently in a survey of transit times for surface drifters in the region [Koszalka et al., 2011b].

[5] However, eddy heat fluxes have never been quantified directly with observational data here. This is the goal of the present paper. Heat fluxes however are notoriously difficult to determine. For one, they are usually dominated by a rotational component which does not contribute to the heat flux divergence [Marshall and Shutts, 1981; Jayne and Marotzke, 2002]. Moreover, separating the rotational and 


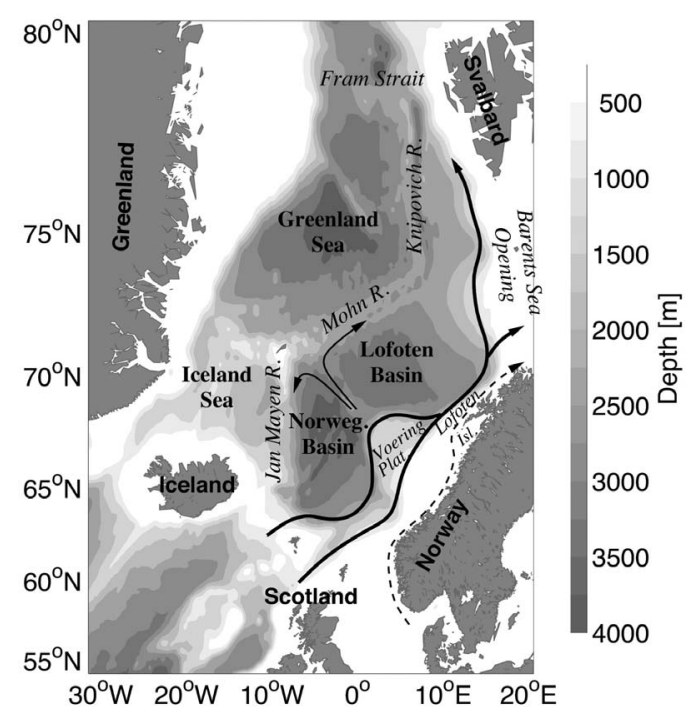

Figure 1. The bottom bathymetry of the Nordic Seas. The Norwegian Atlantic Current (NwAC) flows along the Norwegian coast in an outer and inner branch, separated by the Voering Plateau. They later meet just west of the Lofoten Islands. The Norwegian Coastal Current (NCC) also flows northward, tightly hugging the coast.

divergent components of the fluxes is not trivial. The decomposition for one is not unique [Fox-Kemper et al., 2003], and averaging fluxes appears to have little effect on reducing the rotational component [Griesel et al., 2009]. So interpreting observed fluxes is at best problematic. An option is to focus instead on the divergence of the heat flux, thereby sidestepping the difficulty with the rotational component. Such estimates are generally noisy though, making it difficult to draw conclusions. The determination of fluxes and flux divergences from data is further complicated by their non-Gaussian statistics [Chinn and Gille, 2007], implying that averages converge slowly.

[6] Our approach is to focus on heat flux divergences. We do this not with a single data set, but with data from two different observational sets and a model. The first comprises temperature and velocity measurements from surface drifters in the eastern Nordic Seas. The second involves gridded Sea Level Anomaly (SLA) and Sea Surface Temperature (SST) measurements from satellite. And the third is a 6 yearlong model simulation of the Nordic Seas at eddy-permitting horizontal resolution. Because of observational constraints, we focus on fluxes near the surface and during winter.

\section{Observations and Model}

\subsection{Surface Drifters}

[7] We use the drifter data available under the Global Drifter Program (http://www.aoml.noaa.gov/phod/dac/gdp. html). In the Nordic Seas the data spans the period 19902010 , comprising roughly 100,000 drifter days from over 400 drifters. The same data has been used previously to measure relative dispersion [Koszalka et al., 2009], the time mean surface circulation and eddy statistics [Koszalka et al., 2011a], the time variability of the latter [Andersson et al., 2011] and parcel transit times [Koszalka et al., 2011b]. Each drifter consists of a surface buoy, with a transmitter and a temperature sensor, and a subsurface drogue at 15 meters depth. The buoys are tracked by the Argos satellite system, yielding positions with $150-1000 \mathrm{~m}$ accuracy up to 50 times a day. The temperature measurements are collected $30 \mathrm{~cm}$ under the sea surface and have an accuracy of $0.1{ }^{\circ} \mathrm{C}$. Drifter positions and temperatures were quality controlled and interpolated via a kriging method to yield time series with 6 hour resolution [Lumpkin and Pazos, 2007]. Only trajectory segments from drogued drifters were used. Given that the typical Lagrangian timescale in the Nordic Seas is $T_{L} \sim 1$ day [Poulain et al., 1996; Andersson et al., 2011], tracks shorter than 1 day were discarded. Furthermore, segments for which the time interval between two consecutive data points was longer than 1 day were treated as separate. Drifter positions were filtered with a Butterworth filter with a 26 hour window, to suppress tidal and inertial motions, yielding in total 60,950 drifter days. The zonal and meridional velocities were then derived by center differencing the drifter positions.

[8] The drifter data were processed using a "clustering technique" [Koszalka and LaCasce, 2012]. Rather than collecting observations in bins of fixed geographical dimensions, they were grouped in sets with roughly equal numbers. The result has better statistical uniformity than with regular binning. We employed the $k$ means clustering algorithm in MATLAB to construct sets with $m$ nearest neighbor observations. In this, observations are iteratively assigned to the nearest cluster in a way that minimizes the sum, over all clusters, of the squared distance between cluster members and the cluster center. Koszalka et al. [2001a] showed that using clusters with $m=48$ drifter observations (12 drifter days) produces reliable mean velocity statistics, and we followed the same procedure here. The resulting statistics were assigned to the location of the cluster center, which were thus irregularly distributed. The divergences of fluxes (to be shown later) were calculated from these irregular cluster positions, but the result was finally interpolated onto a $0.2^{\circ} \times$ $0.1^{\circ}$ (lon, lat) grid.

\subsection{Satellite Observations}

[9] We derived surface geostrophic velocities from AVISO's Ssalto/Duacs gridded Sea Level Anomalies (SLA), compiled on $1 / 3^{\circ}$ Mercator grid and updated every 7 days (http://www.aviso.oceanobs.com). The measured anomalies, primarily based on the GFO and Envisat instruments at these latitudes, have an accuracy of 2-3 cm [Robinson, 2004]. The satellites have long repeat cycles (17 and 34 days, respectively) but relatively small track spacing at these latitudes, yielding useful information at scales of a few tens of kilometers. However, the data in the gridded product is substantially smoothed, so it is likely the field underestimates small scale eddy variability.

[10] For Sea Surface Temperature (SST) we use the OSTIA analysis produced by the UK Met Office [Donlon et al., 2011]. The product uses some in situ observations but is primarily based on passive and active satellite products. OSTIA provides an estimate of foundation SST (free of diurnal warming). An optimal interpolation method is used to create daily SST maps on a $1 / 20^{\circ}$ global grid. The bias and accuracy of OSTIA (against in situ observations) are reported to be less than $0.1^{\circ} \mathrm{C}$ and $0.5^{\circ} \mathrm{C}$, respectively. For this study we low pass the daily OSTIA fields to obtain 
a)

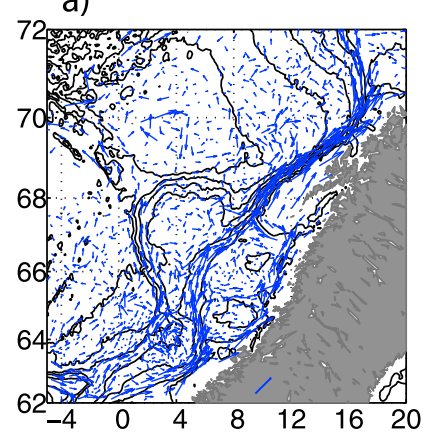

b)

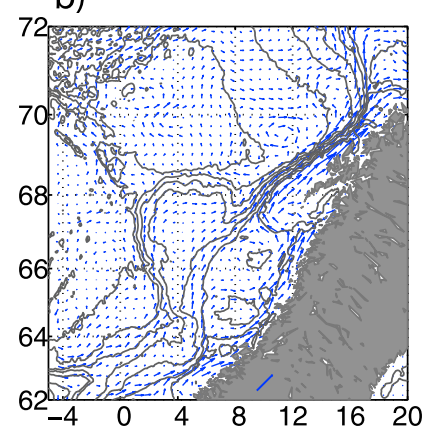

c)

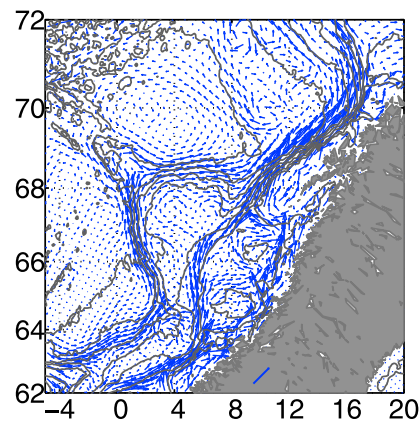

Figure 2. Estimates of winter mean surface currents from (a) drifters, (b) altimeter observations and (c) the model. The drifter estimates are plotted at the positions of the clusters. The vectors drawn on land show the magnitude of a current with speed $0.25 \mathrm{~m} \mathrm{~s}^{-1}$.

weekly mean fields that are interpolated onto the $1 / 3^{\circ}$ Mercator SLA grid for the period 2006-2010.

\subsection{Numerical Model}

[11] For the numerical simulations, we use ROMS [Shchepetkin and McWilliams, 2005, 2009; Haidvogel et al., 2008], a primitive equation model with a free surface and terrain-following vertical coordinates. The model is used for operational forecasting at the Norwegian Meteorological Institute, with a domain that covers the Nordic Seas with roughly $4 \mathrm{~km}$ horizontal resolution. We use a 6 year hindcast spanning the period 2004-2009, forced by ECMWF operational atmospheric analyzes (http://www.ecmwf.int) at the sea surface and a monthly climatology of currents and hydrography [Engedahl et al., 1998] at the lateral boundaries. No further assimilation was used. The model was run with a third-order upwind advection scheme for horizontal momentum and tracers and a vertical advection scheme for tracers based on parabolic spline reconstruction of vertical derivatives. No explicit lateral diffusion was used, but the 3rd order advection scheme has some implicit biharmonic diffusion. Vertical tracer diffusion was parameterized with a General Length Scale scheme [Warner et al., 2005] configured to use a k-epsilon closure. The statistics made below are based on daily averages of the raw model fields.

\section{Results}

\subsection{Mean and Perturbation Fields}

[12] We will focus on the winter season. In the summer, radiative heating is such that it hinders diagnosing lateral

fluxes at the surface. In contrast, the water column in wintertime is well mixed above $15 \mathrm{~m}$ depth, so the sampling at the very surface by satellites and at $30 \mathrm{~cm}$ by drifters should be indicative of the extended surface layer. The region is best sampled by drifters along the path of the NwAC, from about $62^{\circ} \mathrm{N}$ to about $72^{\circ} \mathrm{N}$, with 15,621 drifter days. We therefore confine our attention to eddy fluxes in this region during the period from November to April.

[13] We first decompose the velocity and temperature fields into their respective means and perturbations. Ideally, we would filter the time series to remove the seasonal cycle in temperature. But while such filtering is possible with the model and satellite data, it is not practical with the drifter data, which samples different regions at different times. So instead, we combine all the data collected during the winter months to obtain averages. For consistency, we also use November-April averages for the satellite data and model fields.

[14] Figure 2 shows the winter mean surface currents from the drifters, satellite and the model. The satellite estimate is based on the wintertime SLA plus the CNES-CLS09_v1.1 Mean Dynamic Topography [Rio et al., 2011]. In all three cases the NwAC is clearly seen, with an eastern "inner branch" over the continental slope and a western "outer branch" near the $1500 \mathrm{~m}$ isobath [Orvik and Niiler, 2002]. The Norwegian Coastal Current (NCC) is also seen, near the coast. There are differences however between the sets. The velocities are greater for the drifters and model than for the satellite-derived field, and the drifter means are more spatially variable than the others. These differences reflect specific aspects of the data. The mean velocities are lower with the satellite data because the resolution of the surface height field is fairly coarse and the data has also been smoothed. The higher variability in the drifter field on the other hand is mostly the result of nonuniform temporal sampling.

[15] Notice that the drifters suggest a time mean anticyclonic circulation in the western Lofoten Basin (near $3^{\circ} \mathrm{E}$, $70^{\circ} \mathrm{N}$ ), possible embedded in a larger-scale cyclonic gyre. Anticyclonic flow is not clearly seen in the model, which instead shows a large-scale cyclonic flow in the basin. The satellite observations on the other hand show only a weak flow to the northwest. Previous studies suggest that such an anticyclone exists in the western basin, but that it varies in both strength and position [Köhl, 2007; Rossby et al., 2000; Koszalka et al., 2011a; Andersson et al., 2011]. Some of the drifters were actually deployed in the anticyclone, and the mean fields in the western Lofoten are somewhat biased as a result. The other two mean fields miss it, either because it is has been smoothed out or because of its temporal variability.

[16] The mean SSTs are shown in Figure 3. All three products indicate a warm tongue of water, associated with the inflowing Atlantic water, steered by topography. The warm water tongue is notably broader and more spatially uniform than the mean velocity field. The three products agree in the overall structure of the field but differ somewhat in the details. The drifters and satellite suggest greater spreading of the warm waters offshore than the model. With the latter, the warm water is more strongly constrained by the isobaths, particularly near the outer branch in the south and over the continental slope east of the Norwegian and 
a)

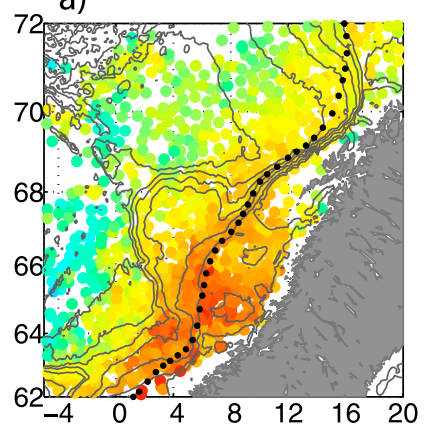

b)

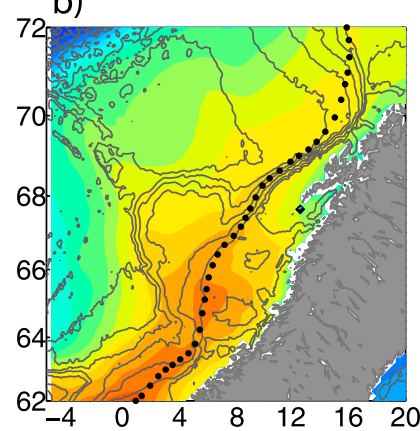

c)

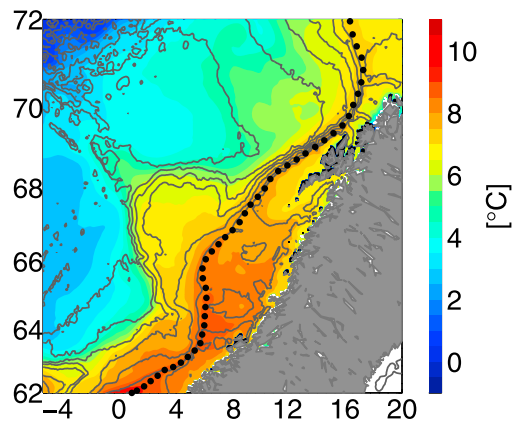

Figure 3. Winter mean surface temperature from (a) drifters, (b) satellite observations and (c) the model. The color scale is the same for all three figures. Also shown are paths following the temperature maximum and used for integrations done in section 3.3.

Lofoten basins. The result is that the interior Lofoten basin is about $1{ }^{\circ} \mathrm{C}$ colder in the model than with the other products.

[17] The RMS perturbation velocities are shown in Figure 4. All three data sets show enhanced variability along the main path of the Atlantic Water. However while the drifter and model exhibit roughly comparable energy levels, the altimeter-derived field is notably weaker. The most pronounced spatial differences are seen in the Lofoten Basin. Here the drifters exhibit high energy levels across the basin, with maxima close to the eastern slope and in the deep central basin around $3^{\circ} \mathrm{E}, 70^{\circ} \mathrm{N}$. The altimeter field suggests elevated variability in these same locations, but with a weaker amplitude. The model on the other hand, while also showing a modest enhancement of energy levels in the deep basin, has the highest variability over the slope.

[18] In this case, each product has a shortcoming at play. The coarse spatial resolution and smoothing in the satellite product results in weaker variability. But the spatial structure of the variance nevertheless resembles that of the drifters. The latter has higher velocities, as essentially all subinertial frequencies are resolved by individual drifters, but the spatial and temporal coverage is irregular. The model variance is comparably high, but it is overly confined to the slope. This suggests excessive topographic control in the model; the eddies aren't penetrating offshore as freely as they should.

[19] The RMS temperatures are shown in Figure 5. In all three cases the variability is on the order of a degree. The variability is enhanced in the Norwegian Basin and close to the Norwegian coast, while it is weak over the Voering Plateau (around $4^{\circ} \mathrm{E}, 67^{\circ} \mathrm{N}$ ) and over the shelf to the a)

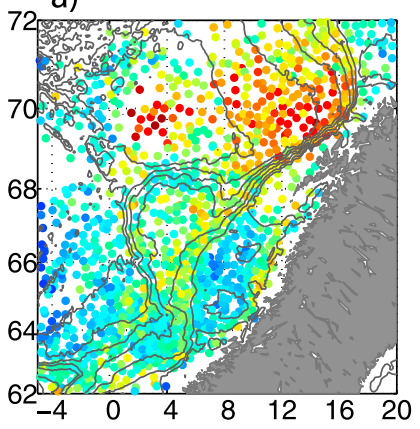

b)

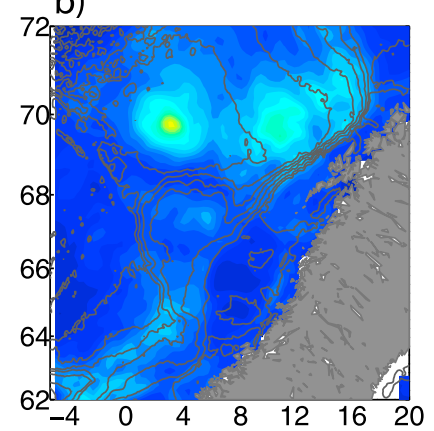

c)

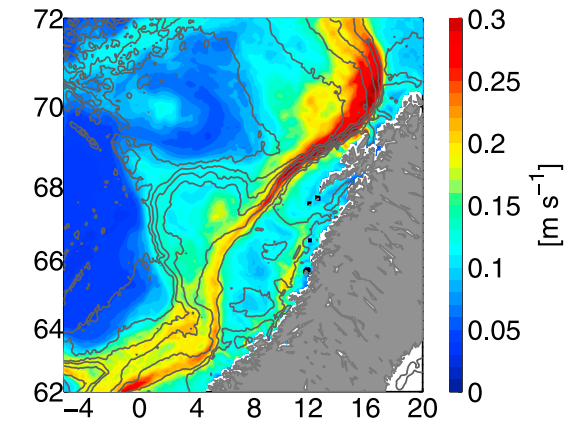

Figure 4. RMS of velocity perturbations (the square root of EKE) from (a) drifters, (b) altimeter observations and (c) the model. The color scale is the same for all three figures.

southeast. The drifters and satellite agree moreover that rms levels are relatively low in the Lofoten Basin. The model, in contrast, shows relatively high variability in this basin. But the greatest temperature variability in the model occurs along the path of the outer branch of the NwAC (Figure 3). a)

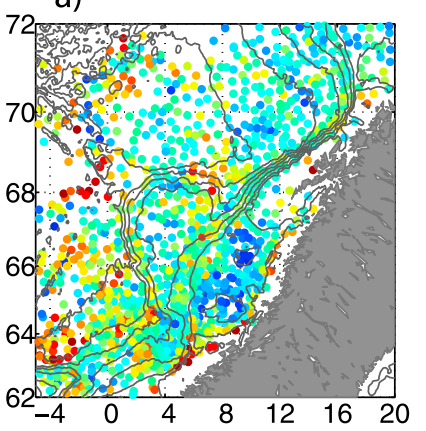

b)

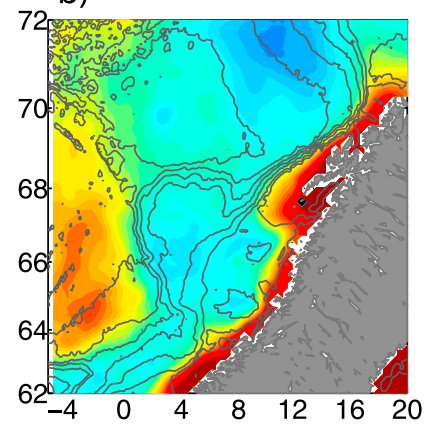

c)

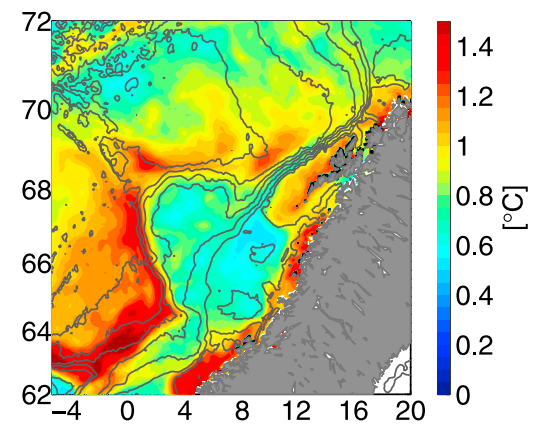

Figure 5. RMS of temperature perturbations from (a) drifters, (b) satellite observations and (c) the model. The color scale is the same for all three figures. 
a)

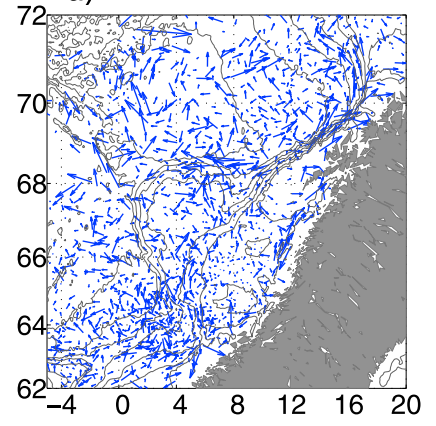

b)

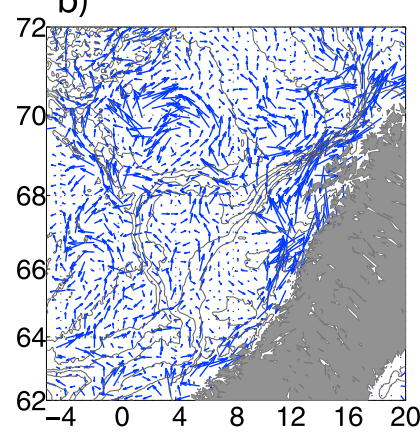

c)

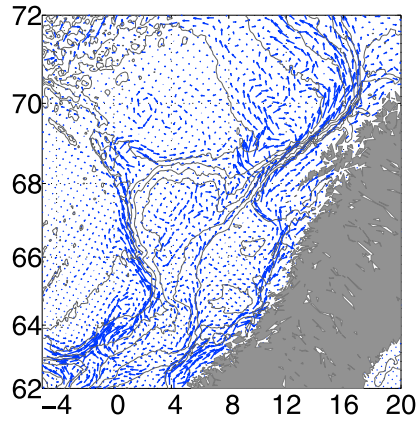

Figure 6. Surface eddy (Reynolds) temperature fluxes from (a) drifters, (b) satellite observations, multiplied by a factor 5 , and (c) the model. The vector scale is arbitrary but the same in the three figures.

This outer branch of the NwAC is associated with a temperature front [Orvik et al., 2001], and lateral motion of the front will induce temperature variability. As the outer branch is strongly steered by topography in the model, these variations are very localized, near the $1500 \mathrm{~m}$ isobath. The drifters and satellite data suggest instead that the variations are more spread out, implying the eddy variability extends further west.

[20] Thus none of the data sets by itself gives a wholly correct picture of the fields. The drifters may most accurately reflect the magnitude of variability, at least for velocities, but the data suffers from nonuniform sampling. The altimeter has more uniform spatial and temporal coverage but underestimates the variability, due to the coarse resolution and smoothing applied. The model, while having the best temporal and spatial sampling of the three, appears to be overly sensitive to the bottom topography. So, as suggested earlier, it is preferable to use all three products simultaneously when considering the eddy field. This is particularly true when looking at the eddy heat flux (being a correlation between the fluctuating velocity and temperature fields), as seen next.

\subsection{Eddy Transport and Transport Convergence}

[21] Now we consider the surface eddy temperature fluxes, defined

$$
\overline{\mathbf{u}^{\prime} T^{\prime}}=\overline{(\mathbf{u}-\overline{\mathbf{u}})(T-\bar{T})},
$$

with the mean velocities $\overline{\mathbf{u}}$ and mean temperatures $\bar{T}$. As before, the averages represent means over the 6 month period from November to April. The three different estimates are shown in Figure 6. Consider the model fluxes first, the cleanest of the three. These are largely aligned with the topography, like the mean currents, and indicate northward eddy-induced heat transport. The fluxes are largest along the western (outer) branch of the NwAC, moving around the Voering Plateau. To the north, the fluxes are greatest over the slope east of the Lofoten Basin. Closer examination suggests that in many locations the eddy fluxes are also slightly offshore, and hence down the mean temperature gradient. This offshore orientation is most evident along the southwestern Voering Plateau and in the eastern Lofoten Basin.

[22] Of the two observational sets, the satellite-derived fluxes are again the weaker. The fluxes have therefore been magnified by a factor 5 for the plot. The drifter fluxes are larger, but are also more disorganized than with the other two sets. The clearest point of agreement is over the slope east of the Lofoten Basin, where all three data sets indicate northward eddy heat transport. All three sets also suggest anticyclonic advection in the western Lofoten Basin, near the semipermanent vortex discussed earlier. The fact that the feature is apparent here but not in the mean velocities of two of the sets is consistent with the vortex being an intermittent feature. But beyond these similarities, the fluxes exhibit significant randomness, suggestive of a strongly eddying field.

[23] The flux divergences are shown in Figure 7. Note we plot the negative of the divergence (the convergence) so that positive values indicate warming. Again, the model field is the easiest to interpret. This displays cooling (negative values, in blue) along both branches of the NwAC. Adjacent to these are red regions, indicating warming. So in the model, the eddies are transporting heat out of the core of the current and warming the surroundings. The warming is intensified in the regions immediately adjacent to the mean current, but there is also a weak signal (light green to yellow) of persistent warming in the deep basins, especially in the northeastern Lofoten Basin. The inshore waters over the shelf are also warming, implying mixing with the shelf waters. Further, the model exhibits eddy fluxes from the Lofoten basin to the Greenland Sea basin across the MohnKnipovich ridge system in the northwest.

[24] The satellite convergences display many similar features. There is cooling along much of the outer branch, southwest of the Voering Plateau and east of the Lofoten Basin. There is also an indication of warming over the shelf, east of the Lofoten Basin. However the regions of warming appear to be more spread out than with the model. The estimate is noisier and the Lofoten Basin in particular has regions of warming and cooling, suggestive of undersampled intermittent activity. It is likely the averages here have not yet converged. The drifter estimates are again the noisiest. In the southern domain, no consistent signal exists. However, the steep slope near the Lofoten Island emerges once again as a region of strong advective cooling. So this at least is consistent with the other sets. The drifters also indicate regions of warming and cooling in the northwest domain, but these occur where there is little data coverage. 
a)

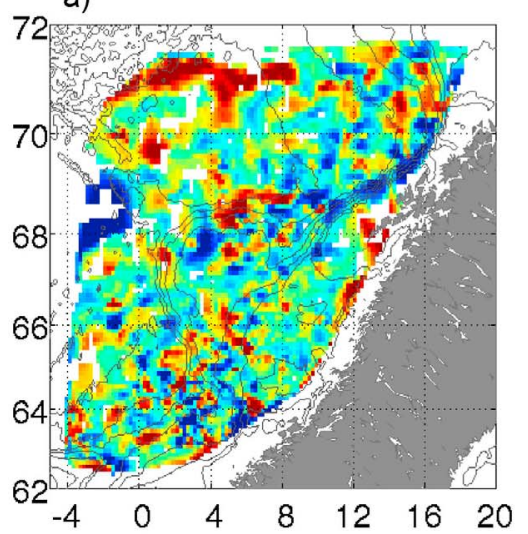

b)

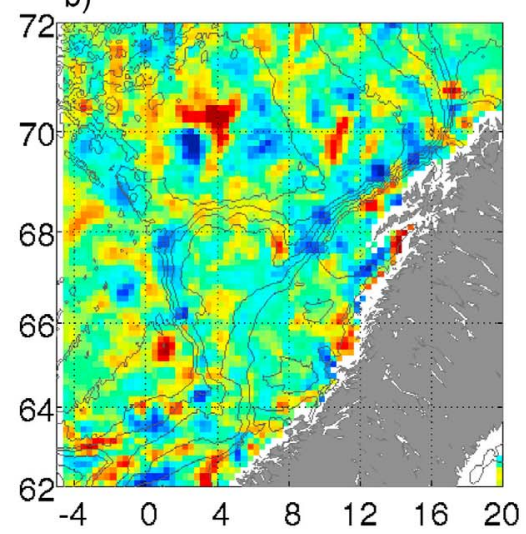

c)

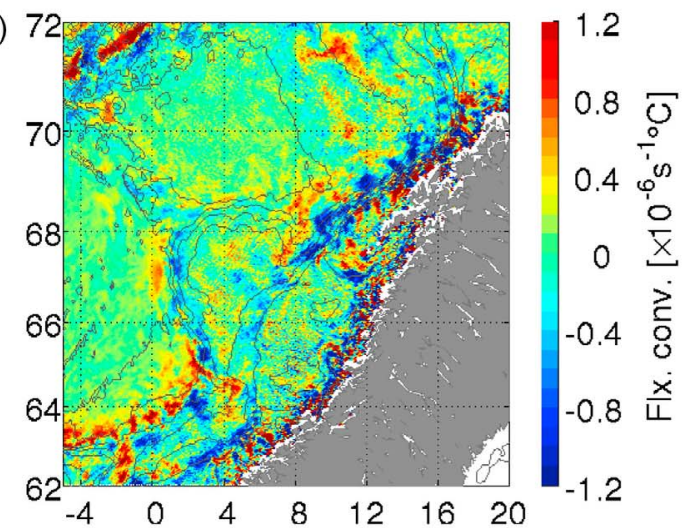

Figure 7. Convergence of eddy temperature fluxes from (a) drifters, (b) satellite observations, multiplied by a factor 5 , and (c) the model. The drifter estimate has been interpolated onto a regular grid (see text). The color scale is the same for all three figures.

[25] The preceding results are fairly typical of the (noisy) divergence estimates one obtains from observations and even from models. But a clearer picture emerges when averaging the divergences over larger areas. We illustrate this by integrating over regions bounded by the mean temperature contours. Then the integrals represent the net effect of the eddies on each of the temperature classes. Such integrated convergences are shown in Figure 8, with estimates of the standard error. The uncertainty was estimated from the year-to-year variability for the satellite and model data and from the variability around the clusters means for drifter data.

[26] The results in the three cases are largely consistent, indicating net advective cooling of the warmer waters and warming of the colder waters. With all three sets, the boundary between warming and cooling is about $6^{\circ} \mathrm{C}$. As can be deduced from Figures 2 and 3 this is roughly the boundary delineating the warm Atlantic waters and the cooler waters of the Nordic Seas. Thus with all three data sets, one would infer that eddy transport divergences are cooling the NwAC and warming the adjacent waters. The drifters and model have the largest magnitudes, while the satellite estimate is weaker (and multiplied by 5 for visibility, as noted). The model fields also indicate eddy-induced cooling of waters in the temperature range $2-3^{\circ} \mathrm{C}$, with warming of even colder waters; this reflects the eddy heat
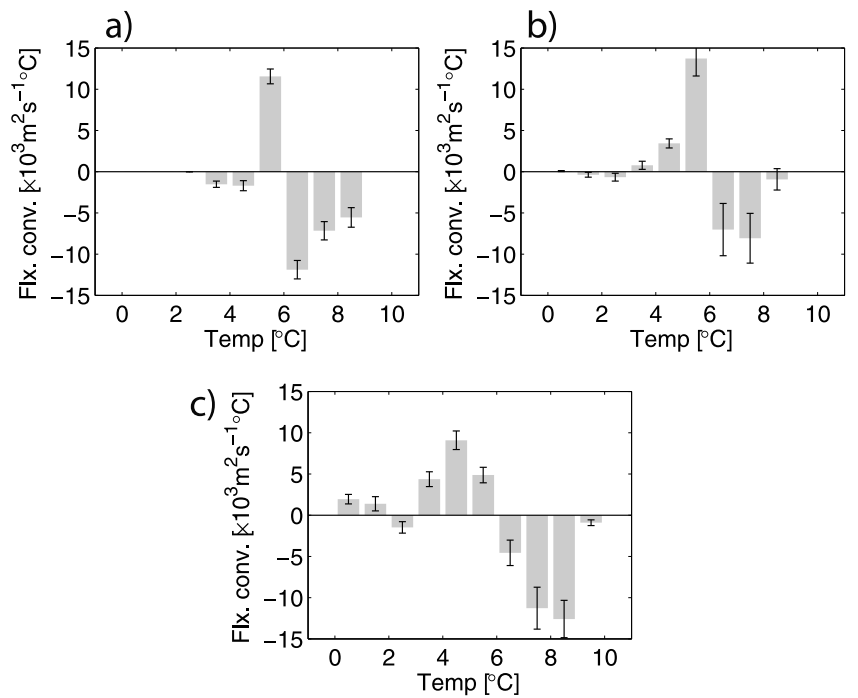

Figure 8. Convergence of eddy temperature fluxes integrated over temperature classes, from (a) drifters, (b) satellite observations, multiplied by a factor 5 , and (c) the model. The error bars represent estimates of the standard error. 

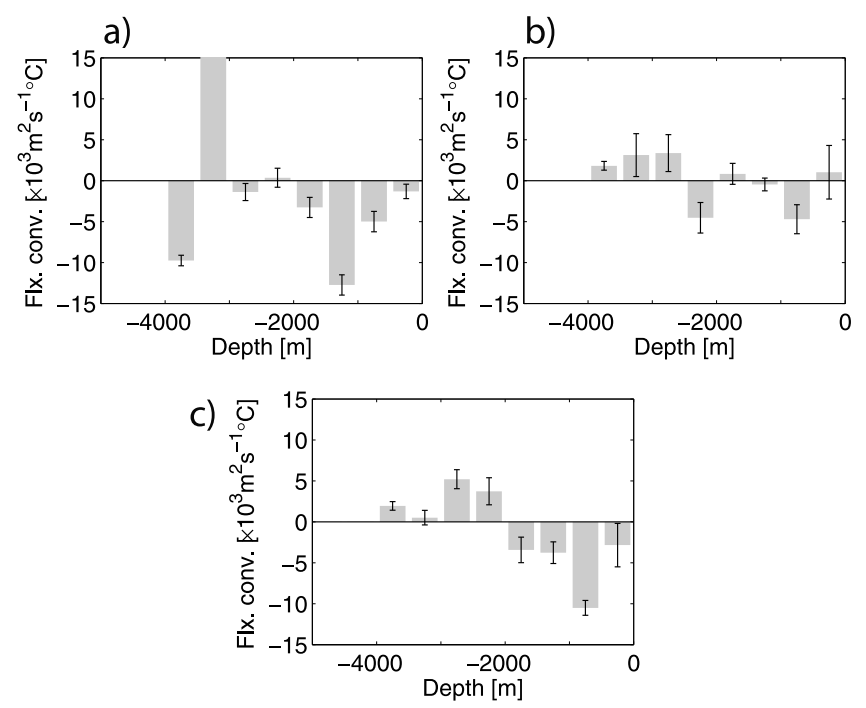

Figure 9. Convergence of eddy temperature fluxes, as in Figure 8, but now integrated over bottom depth classes.

transport across the Mohn-Knipovich ridge seen in Figure 7. The drifter estimate shows cooling of waters with temperatures $1-3^{\circ} \mathrm{C}$, but as most of the drifters were deployed near the coast, the sampling of these cold waters is fairly poor (Figure 6).

[27] Alternately, we can integrate the convergences over ocean depth classes separated by predefined isobaths. The Atlantic Water enters the Nordic Seas over the Greenland Scotland Ridge at depths shallower than 1000-1500 m, and the NwAC is from then on tightly constrained by topography. One would expect eddies to cool the waters residing over ocean depths shallower than 1000-1500 m and to warm waters in deeper regions. The integrations over ocean depth classes is shown in Figure 9. Again, there are large differences between the three estimates: the satellite estimate is noisier at shallower depths and the drifter estimate is again hampered by having relatively few observations from the deep regions in the west. But taken together, the three sets give a clear indication of eddy-induced cooling in regions where the ocean depth is shallower than $2000 \mathrm{~m}$ and warming in deeper regions.

[28] While illuminating, the integrals over temperature or depth classes are less revealing in terms of the transformation of the surface waters during their transit to the north. This can instead be seen by integrating the convergences along the path of the NwAC itself. So we calculate

$$
H_{e}(s)=\int_{0}^{s} \nabla \cdot \overline{\mathbf{u}^{\prime} T^{\prime}} d s^{\prime}
$$

starting at the southern boundary of the domain and following the temperature maximum along the, as traced out in Figure 3. The result is shown in Figure 10. Consider the model result first, shown by the dashed curve in Figure 10c. The integrated convergence is negative, indicating advective cooling by eddies. The integral decreases monotonically moving northward, but the cooling is not constant along the path. Rather, there is pronounced cooling around $69^{\circ} \mathrm{N}$; this is the latitude of the steepest portion of the continental slope, just west of the Lofoten Islands (see Figure 1). The result with the satellite data is similar, albeit with a smaller amplitude (as in earlier plots, the curve has been multiplied by 5 ). The result for the drifter data is also largely consistent, but in this case the cooling occurs almost exclusively east of the Lofoten Basin, near $69^{\circ} \mathrm{N}$. This is in line with the convergences in Figure 7, which are consistently blue only over the steep shelf break there.

[29] To put the eddy fluxes in context, we also integrated the heat flux convergence due to mean advection

$$
H_{m}(s)=\int_{0}^{s} \overline{\mathbf{u}} \cdot \nabla \bar{T} d s^{\prime} .
$$

This, with the contribution from eddies, comprises the total advective flux convergence (we assume the mean velocities are horizontally nondivergent). The result is shown by the solid curve in Figures 10a-10c. In each case, the mean advection is positive, indicating warm advection by the NwAC, and increases monotonically with latitude. The curves indicate moreover that mean advection approximately balances the eddy divergence. Thus in all three cases (the magnitude of the satellite estimate still being uncertain), the divergence of lateral eddy fluxes is evidently responsible for a considerable proportion of the wintertime cooling of the NwAC.

\subsection{Depth Dependence and Seasonality}

[30] To make the above conclusion more general, we require information about the vertical structure and seasonal
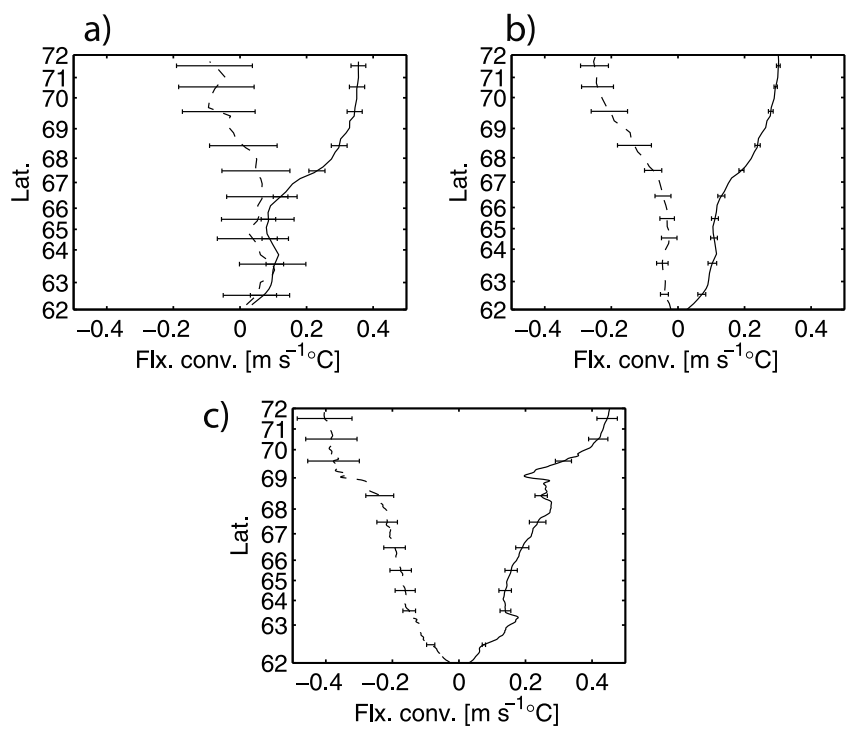

Figure 10. Convergence of surface temperature fluxes integrated along inner branch of the NwAC (defined by the temperature maximum, as shown in Figure 3). From (a) drifters, (b) satellite observations, and (c) the model. Solid lines represent flux convergences by the mean flow (see text) while dashed lines represent convergences by eddy fluxes (the satellite estimate of eddy flux convergence has been multiplied by a factor 5). 
a)

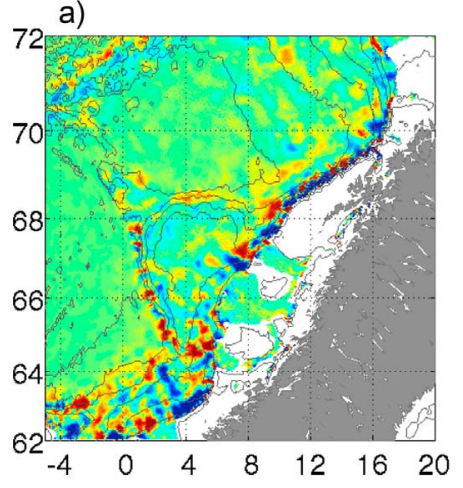

b)

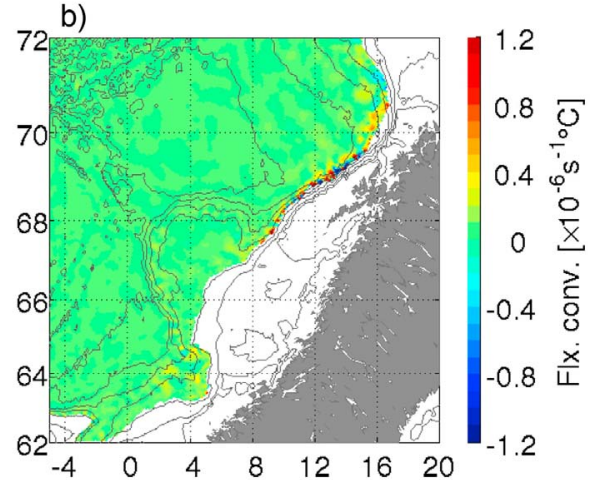

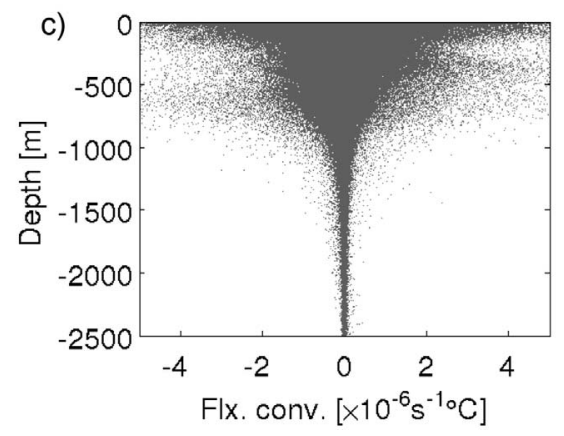

Figure 11. Model estimates of the vertical structure of eddy flux convergences: (a) at $300 \mathrm{~m}$ depth, (b) at $1000 \mathrm{~m}$ depth and (c) scatterplot of flux convergences as a function of depth.

dependence of fluxes. The observational data available to us is of little help, but the model fields can be used as a guide.

[31] Figure 11 shows the model wintertime eddy temperature flux convergence at $300 \mathrm{~m}$ and $1000 \mathrm{~m}$ depth. We see that the flux convergences at $300 \mathrm{~m}$ depth are roughly of the same size as near the surface (Figure 7). But at $1000 \mathrm{~m}$ flux convergences are much weaker, and this is also the case over the continental slope encircling the Voering plateau where the outer branch of the NwAC is flowing. A scatterplot of eddy flux convergences as a function of depth for the entire domain (Figure 11c) suggests that flux convergences are large in the upper few hundred meters of the water column but also generally decay with depth. Evidently eddy fluxes in the model are negligible below about $1000 \mathrm{~m}$. We know of no actual observations from the Nordic Seas that support this picture, but mooring data from around the world oceans generally show a similar decay with depth [Wunsch, 1999].

[32] In light of this possible depth dependence of fluxes, we recalculated integrals (2) and (3) along the NwAC path, but now for the depth-integrated flux convergences in the model. The result, shown in Figure 12 (left), suggests that surface observations in general overestimate flux divergences deeper down and also that the enhanced divergence off the Lofoten islands may be specific to the surface. Also shown (Figure 12, right) are the same estimates made for the summer time (May-October). The model indicates that both mean flow and eddy flux convergences are slightly lower in summer, but it is evident that lateral eddy fluxes act to cool the water column along the NwAC throughout the entire year.
[33] How important is local air-sea cooling of the NwAC in comparison? In the same figure we also present the air-sea temperature flux integrated over the same path

$$
H_{\text {surf }}(s)=\frac{1}{\rho_{0} c_{p}} \int_{0}^{s} Q_{n e t} d s^{\prime},
$$

where $Q_{\text {net }}$ is the net heat flux through the sea surface and $\rho$ and $c_{p}$ are the surface density and heat capacity of waters with salinity 35 and temperature $6^{\circ} \mathrm{C}$ A careful budget calculation is beyond the scope of this study, but some general
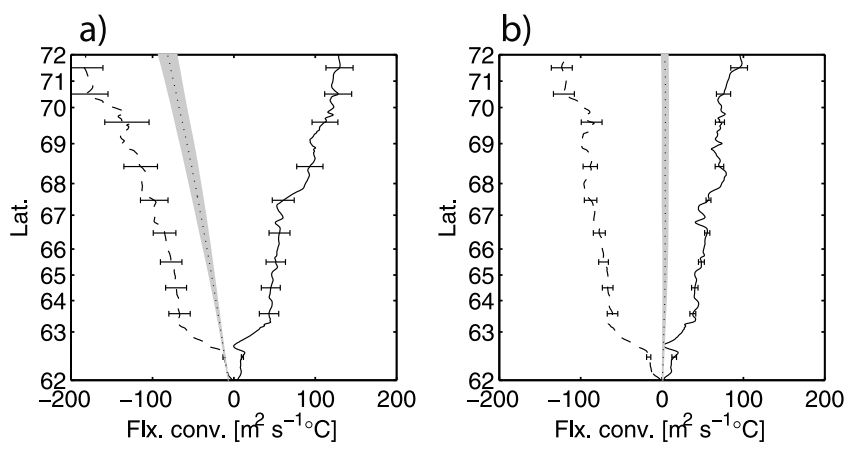

Figure 12. The model transport convergence integrated from top to bottom and along the NwAW path (as in Figure 10): (left) winter months (November-April) and (right) summer months (May-October). Also shown, as gray patches, are estimate of air-sea temperature fluxes integrated along the same path. 
observations can be made. In winter both air-sea fluxes and lateral eddy heat flux divergences evidently act to cool the NwAC. The relative contribution will depend on the depth of the layer considered, but this calculation for the entire water column suggests that eddies are at least as important as air-sea fluxes. And in summer air-sea fluxes even tend to warm the current ever so slightly while eddy flux divergences still act to cool it.

\section{Summary and Discussion}

[34] We compared two observational and one numerical model estimate of mesoscale eddy activity and eddy fluxes in the eastern Nordic Seas, a region of intense heat loss from the ocean to the atmosphere. This represents, to our knowledge, the first mapping out of eddy heat fluxes in this ocean region. And while Lagrangian data has been used previously to estimate heat fluxes in the Southern Ocean [Gille, 2003; Trani et al., 2011], this is the first such attempt in the Nordic Seas.

[35] The three data sets (derived from surface drifters, from surface measurements from satellite and from an eddypermitting operational model) yield estimates of the mean velocities and temperature fields which are largely consistent and which agree with the accepted structure of the respective fields in the region. The data sets are less in accord with regards to the perturbation fields. These differences can be linked to specific aspects of the data. The drifter data has nonuniform coverage in space and time, and perturbation field estimates from this were the noisiest of the three sets. The satellite fields on the other hand are highly smoothed, yielding RMS velocities weaker by a factor of 2-3. And the model eddies, though having uniform coverage and realistically large kinetic energies, are evidently too strongly influenced by the bottom topography. The result is that exchanges with the Lofoten Basin, for example, are weaker in the model than indicated by the other sets.

[36] The eddy heat fluxes differ to an even greater extent. The model fluxes are largely along the isobaths, but with a secondary component directed down the mean temperature gradient. The other data sets yield substantially noisier fields. It is likely that all three realizations are dominated by rotational fluxes, whose intermittency demands more extensive sampling. Taking the divergence of the fluxes exacerbates the noisiness, particularly with the two observational sets. But despite that, several consistent features emerge. Primarily, the steep slope east of the Lofoten Basin is a region of strong advective cooling. The model and satellite suggest that eddy-induced cooling also occurs to the south, particularly near the outer branch of the NwAC. But the drifters do not reveal such cooling; the only consistent signal with this data is the cooling seen near Lofoten.

[37] We found that integrating the divergences over prescribed areas or along a chosen contour reduced the noise. By integrating over the regions bounded by the mean temperature contours, we obtained consistent results with the three sets: that the eddies are cooling the waters warmer than about $6^{\circ} \mathrm{C}$ and warming the cooler waters. Integration over bottom depth ranges instead suggests cooling of waters at depths less than $2000 \mathrm{~m}$ and warming of waters in deeper regions. Finally, integrating the divergences along the mean path of the NwAC revealed that cooling by the eddies is largely balancing warm advection by the mean flow, and that again, the greatest cooling, at least near the surface, occurs as the NwAC passes the Lofoten Basin.

[38] That the eastern Lofoten Basin may be a site of enhanced eddy-induced cooling has been suggested before, by the idealized numerical simulations of Spall [2010b]. There it was found that eddy shedding on the edge of a marginal sea like this occurs preferentially where the slope is steep. The result appears to be at odds with quasigeostrophic linear stability theory, which suggests that a sloping bottom should suppress baroclinic growth [Blumsack and Gierasch, 1972; Mechoso, 1980]. But such theories presume the bottom slope is weak. In cases where the width of the slope approaches that of the mean current, it may be more appropriate to view the topography as a vertical wall, incapable of stabilizing the flow. Such an argument was used in relation to the flow over the slope southwest of Greenland [Bracco et al., 2008; Bracco and Pedlosky, 2003]. Finally, the model fields used here have suggested that the enhancement off Lofoten may be occurring near the surface only. An explanation for this truly intriguing result may be that lower layers are stabilized by the slope (by excitation of topographic waves) whereas upper layers are not [e.g.. LaCasce and Brink, 2000].

[39] In summary, the observations and model data studied here confirm a systematic tendency for eddies to transport heat from the NwAC into the Lofoten and Norwegian basins. The eddy cooling is comparable in magnitude to the warming by the mean current. The study of observations was limited to surface fluxes during winter months, but the three-dimensional model fields suggested that the general conclusions also hold over the entire depth of the Atlantic Water layer and during summer months. A comparison with air-sea fluxes in the model also indicated that eddyinduced cooling of the NwAC is comparable to or larger than local air-sea cooling in winter and completely dominating in summer.

[40] When operational satellite-based salinity data (e.g. from NASA/CONARE's Aquarius mission) become available, first estimates of eddy salinity and, finally, buoyancy fluxes may also be made. However, any proper attempt at closing budgets will require a more refined analysis, including treatment of the vertical distribution of advective fluxes and the time rate of change of the temperature field. Considering the weaknesses of the observational data we have seen here, the use of numerical models is unavoidable. Our model gave the cleanest flux divergences but also showed some systematic problems that discourage a more detailed treatment. A further study of the heat, freshwater and buoyancy budgets in this region with an improved model is therefore desirable.

[41] Acknowledgments. We wish to thank Johan Nilsson and two anonymous reviewers for insightful comments. The work has been funded, in part, by the Norwegian Research Council via the POLEWARD project.

\section{References}

Andersson, M., J. H. LaCasce, I. Koszalka, K. A. Orvik, and C. Mauritzen (2011), Variability of the Norwegian Atlantic Current and associated eddy field from surface drifters, J. Geophys. Res., 116, C08032, doi:10.1029/2011JC007078.

Blumsack, S. L., and P. J. Gierasch (1972), Mars: The effects of topography on baroclinic instability, J. Atmos. Sci., 29, 1081-1089. 
Bracco, A., and J. Pedlosky (2003), Vortex generation by topography in locally unstable baroclinic flows, J. Phys. Oceanogr., 33, 207-219.

Bracco, A., J. Pedlosky, and R. S. Pickart (2008), Eddy formation near the west coast of Greenland, J. Phys. Oceanogr., 38, 1992-2002.

Chinn, B. S., and S. T. Gille (2007), Estimating eddy heat flux from float data in the North Atlantic: The impact of temporal sampling interval, $J$. Atmos. Oceanic Technol., 24, 923-934.

Donlon, C. J., M. Martin, J. D. Stark, J. Roberts-Jones, E. Fiedler, and W. Wimmer (2011), The Operational Sea Surface Temperature and Sea Ice Analysis (OSTIA), Remote Sens. Environ., 116, 140-158, doi:10.1016/ j.rse.2010.10.017.

Eldevik, T., J. E. Ø. Nilsen, D. Iovino, K. A. Olsson, A. B. Sandø, and H. Drange (2009), Observed sources and variability of Nordic Seas overflow, Nat. Geosci., 2, 405-409.

Engedahl, H., B. Ådlandsvik, and E. A. Martinsen (1998), Production of monthly mean climatological archives of salinity, temperature, current and sea level for the Nordic Seas, J. Mar. Syst., 14, 1-26.

Fox-Kemper, B., R. Ferrari, and J. Pedlosky (2003), On the indeterminacy of rotational and divergent eddy fluxes, J. Phys. Oceanogr., 33, 478-483.

Gille, S. T. (2003), Float observations of the Southern Ocean. Part 2: Eddy fluxes, J. Phys. Oceanogr., 33, 1182-1196.

Griesel, A., S. T. Gille, J. Spintall, J. L. McClean, and M. E. Maltrud (2009), Assessing eddy heat flux and its parameterization: A wavenumber perspective from a $1 / 10^{\circ}$ ocean simulation, Ocean Modell., 29 , 248-260.

Haidvogel, D. B., et al. (2008), Ocean forecasting in terrain-following coordinates: Formulation and skill assessment of the Regional Ocean Modeling System, J. Comput. Phys., 227, 3595-3624.

Isachsen, P. E., and O. A. Nøst (2012), The air-sea transformation and residual overturning circulation within the Nordic Seas, J. Mar. Res., 70, 31-68.

Isachsen, P. E., J. H. LaCasce, C. Mauritzen, and S. Häkkinen (2003), Wind-driven variability of the large-scale recirculation flow in the Nordic Seas and the Arctic Ocean, J. Phys. Oceanogr., 33, 2434-2550.

Isachsen, P. E., C. Mauritzen, and H. Svendsen (2007), Dense water formation in the Nordic Seas diagnosed from sea surface buoyancy fluxes, Deep Sea Res., Part I, 54, 22-41.

Jakobsen, P. K., M. H. Ribergaard, D. Quadfasel, T. Schmith, and C. W. Hughes (2003), Near-surface circulation in the northern North Atlantic as inferred from lagrangian drifters: variability from the mesoscale to interannual, J. Geophys. Res., 108(C8), 3251, doi:10.1029/ 2002JC001554.

Jayne, S. R., and J. Marotzke (2002), The oceanic eddy heat transport, J. Phys. Oceanogr., 32, 3328-3345.

Katsman, C. A., M. A. Spall, and R. S. Pickart (2004), Boundary current eddies and their role in the restratification of the Labrador Sea, J. Phys. Oceanogr., 34, 1967-1983.

Köhl, A. (2007), Generation and stability of a quasi-permanent fortex in the Lofoten Basin, J. Phys. Oceanog., 37, 2637-2651.

Koszalka, I., and J. H. LaCasce (2012), Lagrangian analysis by clustering, Ocean Dyn., 60, 957-972, doi:10.1007/s10236-010-0306-2.

Koszalka, I., J. H. LaCasce, and K. A. Orvik (2009), Relative dispersion in the Nordic Seas, J. Mar. Res., 67, 411-433.

Koszalka, I., J. H. LaCasce, M. Andersson, K. A. Orvik, and C. Mauritzen (2011a), Surface circulation in the Nordic Seas from clustered drifters, Deep Sea Res., Part I, 58, 468-485.

Koszalka, I., C. Mauritzen, and J. H. LaCasce (2011b), In pursuit of anomalies-Analyzing the poleward transport of Atlantic Water with surface drifters, Deep Sea Res., Part II, in press.

LaCasce, J. H., and K. H. Brink (2000), Geostrophic turbulence over a slope, J. Phys. Oceanogr., 30, 1305-1324.

Lilly, J. M., P. B. Rhines, F. Schott, K. Lavender, J. Lazier, U. Send, and E. D'Asaro (2003), Observations of the Labrador Sea eddy field, Prog. Oceanogr., 59, 75-176.

Lumpkin, R., and M. Pazos (2007), Measuring surface currents with Surface Velocity Program drifters: The instrument, its data, and some recent results, in Lagrangian Analysis and Prediction of Coastal and Ocean Dynamics, edited by A. Griffa et al., pp. 39-67, Cambridge Univ. Press, Cambridge, U. K.
Marshall, J., and G. Shutts (1981), A note on rotational and divergent eddy fluxes, J. Phys. Oceanogr., 11, 1677-1680.

Mauritzen, C. (1996a), Production of dense overflow waters feeding the North Atlantic across the Greenland-Scotland Ridge. Part 1: Evidence for a revised circulation scheme, Deep Sea Res., Part I, 43, 769-806.

Mauritzen, C. (1996b), Production of dense overflow waters feeding the North Atlantic across the Greenland-Scotland Ridge. Part 2: An inverse model, Deep Sea Res., Part I, 43, 807-835.

Mechoso, C. R. (1980), Baroclinic instability of flows along sloping boundaries, J. Atmos. Sci., 37, 1393-1399.

Nøst, O. A., and P. E. Isachsen (2003), The large-scale time-mean ocean circulation in the Nordic Seas and the Arctic Ocean estimated from simplified dynamics, J. Mar. Res., 61, 175-210.

Orvik, K. A., and P. P. Niiler (2002), Major pathways of Atlantic water in the northern North Atlantic and the Nordic Seas toward the Arctic, Geophys. Res. Lett., 29(19), 1896, doi:10.1029/2002GL015002.

Orvik, K. A., Ø. Skagseth, and M. Mork (2001), Atlantic inflow to the Nordic Seas: Current structure and volume fluxes from moored current meters, VM-ADCP and SeaSoar-CTD observations, 1995-1999, Deep Sea Res., Part I, 48, 937-957.

Poulain, P.-M., A. Warn-Varnas, and P. P. Niiler (1996), Near-surface circulation of the Nordic Seas as measured by lagrangian drifters, J. Geophys. Res., 101, 18,237-18,258.

Rio, M. H., S. Guinehut, and G. Larnicol (2011), New CNES-CLS09 global mean dynamic topography computed from the combination of GRACE data, altimetry, and in situ measurements, J. Geophys. Res., 116, C07018, doi:10.1029/2010JC006505.

Robinson, I. S. (2004), Measuring the Oceans From Space: The Principles and Methods of Satellite Oceanography, Springer, Berlin.

Rossby, T., V. Ozhigin, V. Ivshin, and S. Bacon (2000), An isopycnal view of the Nordic Seas hydrography with focus on properties of the Lofoten Basin, Deep Sea Res., Part I, 56, 1955-1971.

Segtnan, O. H., T. Furevik, and A. D. Jenkins (2011), Heat and freshwater budgets of the Nordic Seas computed from atmospheric reanalysis and direct ocean observations, J. Geophys. Res., 116, C11003, doi:10.1029/ 2011JC006939.

Shchepetkin, A. F., and J. C. McWilliams (2005), The Regional Oceanic Modeling System (ROMS) a split-explicit, free-surface, topography following-coordinate oceanic model, Ocean Modell., 8, 347-404.

Shchepetkin, A. F., and J. C. McWilliams (2009), Correction and commentary for "Ocean forecasting on terrain-following coordinates: Formulation and skill assessment for the Regional Ocean Modeling System" by Haidvogel et al., J. Comput. Phys., 227, 3595-3624.

Spall, M. A. (2004), Boundary currents and water mass transformation in marginal seas, J. Phys. Oceanogr., 34, 1197-1213.

Spall, M. A. (2005), Buoyancy-forced circulations in shallow marginal seas, J. Mar. Res., 63, 729-752.

Spall, M. A. (2010a), Dynamics of downwelling in an eddy-resolving convective basin, J. Phys. Oceanogr., 40, 2341-2347.

Spall, M. A. (2010b), Non-local topographic influences on deep convection: An idealized model for the Nordic Seas, Ocean Modell., 32, 72-85.

Straneo, F. (2006), Heat and freshwater transport through the central Labrador Sea, J. Phys. Oceanogr., 36, 606-628.

Trani, M., P. Falco, and E. Zambianchi (2011), Near-surface eddy dynamics in the Southern Ocean, Polar Res., 30, 11203, doi:10.3402/polar. v30i0.11203.

Voet, G., D. Quadfasel, K. A. Mork, and H. Søiland (2010), The mid-depth circulation of the Nordic Seas derived from profiling float observations, Tellus A, 62, 516-529, doi:10.1111/j.1600-0870.2010.00444.x.

Walin, G., G. Broström, J. Nilsson, and O. Dahl (2004), Baroclinic boundary currents with downstream decreasing buoyancy: A study of an idealized Nordic Seas system, J. Mar. Res., 62, 517-543.

Warner, J. C., C. R. Sherwood, H. G. Arango, and R. P. Signell (2005), Performance of four turbulence closure models implemented using a generic length scale method, Ocean Modell., 8, 81-113.

Wunsch, C. (1999), Where do ocean eddy heat fluxes matter?, J. Geophys. Res., 104(C6), 13,235-13,249. 